\title{
Teaching With Charisma
}

\section{James D. Milojkovic}

Whether and how far the capacity for imagination can be stimulated by higher education, I do not know. I am quite sure however, that it can be dulled, even killed by overemphasis on the importance of information and discipline. Yet without discipline, no skills can be acquired. And without a solid respect for facts, imagination degenerates into empty phantasy....

The crucial question is ... how to encourage discipline without strifling imagination.

\section{Philip K. Rhinelander}

Professor of Philosophy Emeritus

\begin{abstract}
Although research on teacher effectiveness has been carried out for more than 60 years, few consistent relationships have been established between teacher variables and effectiveness criteria (Doyle, 1977). While this effort continues, my purpose here is to suggest that a new approach to studying teacher effectiveness and an answer to Rhinelander's "crucial question" can be found by focusing on the nature and development of charismatic teaching. The underlying assumption of my approach is that the essence of highly effective teaching does not constitute a mystery understood by only a few "born" teachers. I believe that an analysis of the qualities of charismatic teaching will shed new light on the teaching process and provide the basis for new teacher training techniques for higher education.
\end{abstract}




\section{Cold Cognition vs. Hot Cognition}

Recently, Snow, Federico, and Montague (1980a, 1980b) edited two volumes on the progress of cognitive analyses in education. In reviewing these volumes Baron (1981) concluded:

The work in these volumes ... seems to assume that the purpose of instruction is to teach specific skills and knowledge, such as arithmetic. The uses of instruction to teach general styles and strategies of thinking, to protect students from common fallacies of reasoning, to teach critical thinking, to instill an appreciation of truth, beauty, and morality are neglected. This limitation is, of course, the result of the particular point of view chosen. But it must be remembered that this point of view is one among many. To forget this is to encourage an ideology in which people think of themselves as the theory pictures them, as modules capable of certain functions in a larger system of information processing. (p. 514)

Baron's comments stem from a rejection of the idea that there exists a complete information-processing theory of the human learner. In much of the empirical work inspired by the man-qua-informationprocessor metaphor questions of "hot cognition" such as the nature of the interplay between emotion and rationality are avoided in favor of the presumed primacy and more fundamental nature of "cold cognition." Affect is viewed as post-cognitive and in consequence is downplayed (Zajonc, 1980). The banishment of affect is even more the norm in teaching. Little wonder that affect-laden topics such as "truth, beauty, and morality" are neglected.

Much of higher education stresses the elimination of affect in exchange for cool, analytic detachment whereby insight is not hampered by emotion. The idealized picture of the impartial scholar who engages in logically precise research is the traditional norm to which we wish our students to aspire. Unfortunately, all too many classroom presentations seem to be based on a similar even-handed approach that robs fascinating subject matter of its intellectual richness and converts it to a bland assemblage of lukewarm facts to be digested for yet another examination. Not surprisingly, students confronted with the "average" teacher are often left baffled why anyone would devote his or her life to the study of such limp material. 
While it is true that the traditional lecture format is a most inefficient means of transferring information, one must not underestimate the powerful affective impact that a live lecture can deliver. The charismatic teacher can engender an enthusiasm that may not only ignite a fierce desire for more knowledge and deeper understanding but may also spark a career. Lest I be accused of promoting bald "educational seduction," let me hasten to point out emphatically that the paramount danger is not seduction but boredom. For the great majority of students, higher education is already sufficiently impersonal to lead most of them to believe that no one cares enough to bother to intellectually seduce them!

\section{A Profile of the Charismatic Teacher}

Those of us fortunate enough to have been the students of charismatic teachers have marvelled at their exceptional ability to rivet our attention not only for a full class period but, more strikingly, over the entire course or school year. The electric quality pervading their classrooms creates a deep impression that is fondly remembered, much admired, and yet poorly replicated in the classrooms of other teachers with equal knowledge and experience.

In order to nurture the development of qualities inherent to truly inspiring teaching, it is necessary first to identify these qualities. Below I present a profile of the quintessential charismatic teacher taken from Milojkovic and Zimbardo (1980). It is based on our own classroom experiences as students of electrifying masters. (There are clear parallels with charismatic political and social leaders.) [Note: Since the attribute of charisma is not gender specific, the words "she" and "her" should be read as "s/he" and "her/his" throughout the following.]

- Total Mastery: The charismatic teacher appears to be the absolute master of her domain of expertise. Every concept presented appears to have been fully thought through.

- Joy in the Quest for Understanding: Her delight with her field is directly apparent and immediately communicated. Self-disclosures reveal the sophisticated processes of thought that have led to her present conceptualization of the domain under discussion. 
- Insatiable Curiosity: She is never satisfied with her current level of understanding but continually seeks deeper and fuller explanations. She learns from every teaching encounter since she is open to new ideas regardless of their source.

- Sincerity: She has a genuine belief in the importance of her field and has committed herself to furthering it.

- Flawless Presentation: Her apparently effortless delivery is smooth and precise. Technical details have been attended to so that all flows like clockwork.

- Overt Assertiveness: She proclaims her interpretations and analyses with the vigor of one convinced of internal consistency and global completeness. Everything about her manner smacks of assertive drive and she projects an infectious air of confidence that permeates the entire classroom.

- High Energy Level: Nothing is approached half-heartedly. Every action is powered with a dynamic force.

- Dramatic Appreciation: She has a profound sense of the dramatic combined with an acute appreciation of timing.

- Clear Affect: She does not hesitate to express her emotional reaction to any facet of her endeavor. Her facial expression, gross body movements and tone of voice all combine to clearly indicate her affective response.

- Positive Self-Image: She regards herself in a positive light and conveys no doubts concerning her self-worth.

- Sense of Perspective: Her power of thought is accentuated by a remarkably clear perception of the context of her discipline and of the importance of outstanding problems in the field.

- Unity of Purpose: She reveals to her students the path they should take toward a commonly shared goal - the enrichment of both intellect and spirit.

\section{Developing a Charismatic Teaching Style}

While I agree with the proposition that not every teacher can become charismatic, I do not subscribe to the view that only a gifted few can ever expect to achieve such distinction. Ideas for highly effective teaching rarely happen as if by divine revelation. More often 
than not, they are the end product of arduous and well-organized cognitive activity impelled by a burning desire to do a superb job. For each of the abstract principles of charismatic teaching outlined above, a set of operational tactics and strategies can be realized. Such a program for charismatic teaching is currently being developed by a teaching-research team at Stanford University. One of the underlying premises of this program is that the "macro" skill of highly effective teaching can be achieved through the mastery and combination of a number of "micro" communication and social skills. For example, participants are urged to enroll in courses on public speaking, assertiveness, and sometimes even drama. This list might strike some as being more in tune with training for the stage rather than for teaching at the college level. It is important to realize, however, that dynamic teaching is a social interaction with the teacher playing the role of leader. Consequently, if we are to produce highly effective teachers it is imperative that they are not only masters of their subject areas but that they also have a keen understanding of group dynamics, develop excellent social skills, and learn how to display a range of leadership styles.

Through the courtesy of the Center for Teaching and Learning at Stanford progress in achieving teaching excellence is monitored by videotaping actual classroom presentations several times during the course of the quarter. Participants view their own and others' tapes in a warm supportive atmosphere where both successes and failures are closely studied and discussed at length. Our emphasis throughout is not to settle for merely good teaching but to constantly strive for superb teaching that excites and inspires.

\section{Towards Charismatic Teaching}

In giving workshops on developing teaching style, I stress that highly effective teaching can be defined by a set of learnable attitudes, behaviors and skills, and not exclusively by innate traits possessed by an individual. During the course of these workshops, participants engage in a number of exercises designed to enhance classroom communication skills. For example, one exercise involves workshop members preparing a 5-10 minute talk on a topic they consider to be 
one of the most interesting in their discipline. They then deliver this mini-lecture playing the role of the most boring instructor they have ever had. After a group discussion of the finer features of the muchpracticed art of being boring, participants are urged to think about the overt behaviors of charismatic teachers. They regive their talk displaying these behaviors to the group and to a videotape camera. These tapes form the basis for further group discussion about the distinctions between the assertive versus the aggressive teacher, the dynamic versus the overbearing teacher, and the effective educator versus the merely flamboyant showperson.

Other exercises include having workshop members practice various mnemonic techniques for greater classroom impact. These memory aids are invaluable for transforming impersonal lectures into dramatic, compelling intellectual events. Student names and faces are readily mastered so that they can be directly addressed during the course of a lecture which can now be delivered without a dependence on notes.

It should be clear that these and other exercises practiced in the workshops are short-term experiences that serve to highlight only some of the features of outstanding teaching. In addition, one must adopt a long-term approach to effective teaching during which various techniques are sought, tried and discarded as appropriate. As a first step, one might visit the classes of instructors who are well-known for their teaching and pay particular attention to their methodology. Next, one could work on structuring one very special lecture incorporating unusually potent examples, analogies and, if appropriate, audio-visual materials. Developing this lecture clearly involves extra time and thought devoted to meticulous preparation and rehearsal. Although such an effort is not without its costs, experimentation with one's teaching wards off burn-out for both the instructor and the students. After delivering the lecture, actively solicit student feedback, act on that feedback, and give the lecture again as soon as possible. Once that lecture is fine-tuned, aim for a second, then a third, and so on. 


\section{The Challenge of Charismatic Teaching}

Instructional psychology is making impressive gains with its cognitive orientation. However, as Wittrock (1974) has pointed out, the production of fundamental advances in the understanding of human learning and its facilitation needs to stem from the study of cognitive and affective processes. The challenge of analyzing and developing charismatic teaching may lead to greater understanding of both these processes in the college classroom.

\section{References}

Baron, J. The use of cognitive analyses. Contemporary Psychology, 1981, 26, 512-514.

Milojkovic, J.D. and Zimbardo, P.C. Charismatic teaching: Its nature and development. Paper presented at the Sixth International Conference on Improving University Teaching. Lausanne, Switzerland, July, 1980.

Snow, R.F., Federico, P-A., and Montague, W. (Eds.) Aptitude, learning and instruction, Vol. 1: Cognitive process analysis of aptitude. Hillsdale, N.J.: Frlbaum, 1980a.

Snow, R.F., Federico, P-A., and Montague, W. (Eds.) Aptitude, learning and instruction, Vol. 2: Cognitive process analysis of learning and problem solving. Hillsdale, N.J.: Frlbaum, 1980b.

Wittrock, M.C. Learning as a generative process. Educational Psychologist, 1974, 11, 87-95.

Zajonic, R.B. Feeling and thinking: Preferences need no inferences. American Psychologist, 1980, 35, 151-175. 